\title{
Medical management of ectopic pregnancy in a low resource setting: the role of methotrexate
}

\author{
Simon Birame Ndour*, Mamour Gueye, Abdoul Aziz Diouf, Moussa Diallo
}

Department of Medicine, Cheikh Anta DIOP University, Dakar, Senegal

Received: 07 January 2021

Accepted: 09 February 2021

\section{*Correspondence:}

Dr. Simon Birame Ndour,

E-mail: simonndour1@yahoo.fr

Copyright: (c) the author(s), publisher and licensee Medip Academy. This is an open-access article distributed under the terms of the Creative Commons Attribution Non-Commercial License, which permits unrestricted non-commercial use, distribution, and reproduction in any medium, provided the original work is properly cited.

\begin{abstract}
Background: Medical treatment using methotrexate. However, its indications and the protocol of administration are still under discussion. Even if follow-up problems are often raised in developing countries, medical treatment of ectopic pregnancy remains a reasonable option that we practice and share our experience here.

Methods: We performed a retrospective cohort study of patients managed for an unruptured ectopic pregnancy in two university hospital facilities in Dakar: the Centre Hospitalier National de Pikine and the Centre de Santé de Philipe Maguilen Senghor. The data of this study are spread over a period of 10 years, from 2010 and 2019. We planned to evaluate maternal age, parity, gestational age, diagnosis circumstances, medical management, monitoring, and outcome. A single dose protocol was used. Data extracted from the registries were transferred to Microsoft Excel 2019, Mac version and then moved to SPSS (Statistical Package for Social Sciences, 26.

Results: Over ten years, we had registered 18 patients who had received medical treatment out of a total of 263 ectopic pregnancies treated in the two facilities, i.e., a frequency of $6.8 \%$. The average age was 28.8 years. The average initial HCG level was 10,460 mIU/ml. Treatment succeeded in more than 6 out of 10 patients $(61.1 \%)$. However, we noted 5 cases of failure that had secondarily benefited from salpingectomy by laparotomy.

Conclusions: Methotrexate is now part of the therapeutic arsenal in the management of unruptured tubal ectopic pregnancies. However, in developing countries, particularly in Senegal, there is a reluctance to use this therapeutic method, which, however, when a personalized follow-up is carried out, is achievable with a success rate comparable to other therapeutic methods.
\end{abstract}

Keywords: Dakar (Senegal), Ectopic pregnancy, Low resource, Methotrexate

\section{INTRODUCTION}

Ectopic pregnancy is the implantation and development of the egg outside the uterine cavity. ${ }^{1}$ The inflammatory sequelae of Chlamydia trachomatis infection are among the leading causes of ectopic pregnancy. ${ }^{2}$ Its diagnosis has benefited from the development of ultrasound, the particularly improved resolution with high-frequency probes, and biology with the determination of gonadotropic chorionic hormone. Formerly surgical and performed by laparotomy, the treatment of ectopic pregnancy has been de-escalated with the advent of endoscopic surgery and medical treatment with methotrexate. ${ }^{3,4}$ Unruptured ectopic pregnancies, $95 \%$ of ectopic pregnancies can benefit from endoscopic management if the technical platform allows it. ${ }^{5}$ Based on hospital data, ruptured ectopic pregnancies still occupy the leading group, so that the simple reference to it triggers in the mind of the physician (surgeon or obstetrician) the entire cascade of management of a hemorrhagic emergency by laparotomy. However, for some patients seen early on, a more conservative 
alternative should be offered, such as medical treatment. Medical treatment using methotrexate, introduced in the management of ectopic pregnancy since the 1980s, has gained ground over the years and has finally demonstrated its efficacy in unruptured forms. ${ }^{6,7}$ However, its indications and the administration protocol of are still under discussion. ${ }^{8,9}$ Its obvious advantages, relative efficacy compared to standard gold, and its safety are attracting more and more practitioners and patients. Even if problems of follow-up are often raised in developing countries, medical treatment of ectopic pregnancy remains a reasonable option that we practice and share our experience here.

\section{METHODS}

It was a retrospective cohort study of patients managed for an unruptured ectopic pregnancy in two university hospital facilities in Dakar: the Centre Hospitalier National de Pikine and the Centre de Santé de Philipe Maguilen Senghor. These two facilities record an average of 7,000 deliveries per year, including 50 to 60 ectopic pregnancies. The data of this study are spread over a period of 10 years, from 2010 and 2019.

\section{Usual treatment of ectopic pregnancy in both hospitals}

In both hospitals, the treatment of ectopic pregnancy is usually performed by laparotomy or endoscopy surgery. Whether performed by laparotomy or endoscopy, the procedure is most often radical, ie, a salpingectomy.

\section{Inclusion criteria}

We included all patients who had received medical treatment for an ectopic pregnancy during the study period at both centers.

\section{Exclusive criteria}

Patients with incomplete data in their records were not included in the study.

\section{Variables assessed}

We planned to evaluate maternal age, parity, gestational age, circumstances of diagnosis, medical management, monitoring and outcome.

\section{Data collection method}

In each of the two facilities, there is a software program for data collection, which can be recorded retrospectively and prospectively. Patient data for this study were extracted from these electronic registries.

\section{Data analysis}

Data extracted from the registries were transferred to Microsoft Excel 2019, Mac version and then moved to
SPSS (Statistical Package for Social Sciences, 26). Mean, median, and standard deviation were considered to describe continuous variables while frequencies were reported for categorical and nominal variables. Pearson correlation was computed to evaluate the association between continuous quantitative variables.

\section{RESULTS}

\section{Socio-demographic characteristics}

Over ten years, we had registered 18 patients who had received medical treatment out of a total of 263 ectopic pregnancies treated in the two facilities, i.e., a frequency of $6.8 \%$. The average age was 28.8 years, with extremes at 20 and 36 years. A proportion of $22.2 \%$ of patients had a history of ectopic pregnancy treated surgically.

\section{Clinical data}

Metrorrhagia was present in $50 \%$ of cases, associated with pelvic pain in $16.7 \%$ of cases. Patients were asymptomatic in $38.9 \%$ of cases, the diagnosis was solely made by ultrasound. However, all patients had benefited from an ultrasound scan to confirm the diagnosis. The average initial HCG level was $10,460 \mathrm{mIU} / \mathrm{ml}$ with extremes of 162.5 and $87,110 \mathrm{mIU} / \mathrm{ml}$. The mean gestational age was seven weeks' gestation (WG) with extremes of $5 \mathrm{WG}$ and $9 \mathrm{WG}+4$ days. Table 1 shows the socio-demographic and clinical characteristics of the patients.

\section{Treatment}

A single dose protocol was used. It consisted of an intramuscular injection of Methotrexate at a dose of $1 \mathrm{mg}$ per kilogram; a pre-therapeutic assessment was carried out beforehand, namely the level of plasma chorionic gonadotropic hormone (hCG), a blood count, liver transaminases and creatinine levels. Monitoring by weekly dosing was carried out. All patients had a physician who personally monitored their progress. A single-dose protocol was used in our patients. Additional doses were given in $16.7 \%$ of patients. All patients were hospitalized for 3 to 4 days after initiation of treatment to monitor and manage possible side effects of Methotrexate or ruptured ectopic pregnancy.

\section{Outcome}

Treatment succeeded in more than 6 out of 10 patients $(61.1 \%)$, as shown in Table II. However, we noted 5 cases of failure that had secondarily benefited from salpingectomy by laparotomy. One of them was an ectopic pregnancy with a live $9 \mathrm{WG}$ embryo. Two patients were lost to follow-up. Success was not correlated with the initial hCG level. However, we found a moderate correlation $(\mathrm{r}=0.6, \mathrm{p}=0.027)$ ) between gestational age in days and time to achieve undetectable hCG levels, as shown in Figure 1. 
Table 1: Clinical characteristics of patients with ectopic pregnancy.

\begin{tabular}{|c|c|c|c|c|c|c|c|c|c|}
\hline Case & Age & Gestity & Parity & $\begin{array}{l}\text { Living } \\
\text { Living } \\
\text { child }\end{array}$ & $\begin{array}{l}\text { History } \\
\text { of EP }\end{array}$ & $\begin{array}{l}\text { History } \\
\text { of STIs }\end{array}$ & $\begin{array}{l}\text { Treatment } \\
\text { with } \\
\text { progestins }\end{array}$ & Symptoms & $\begin{array}{l}\text { Gestational } \\
\text { age }\end{array}$ \\
\hline 1 & 29 & 1 & 0 & 0 & Yes & No & No & $\begin{array}{l}\text { Pelvic } \\
\text { pain+metrorrhagia }\end{array}$ & $7 \mathrm{WG}$ \\
\hline 2 & 20 & 1 & 0 & 0 & No & No & No & Metrorrhagia & $6 \mathrm{WG}$ \\
\hline 3 & 27 & 1 & 0 & 0 & No & No & No & Ultrasound & $7 \mathrm{WG}$ \\
\hline 4 & 29 & 2 & 1 & 1 & No & No & No & $\begin{array}{l}\text { Pelvic } \\
\text { pain+metrorrhagia }\end{array}$ & $5 \mathrm{WG}$ \\
\hline 5 & 31 & 2 & 1 & 1 & No & No & No & Metrorrhagia & $7 \mathrm{WG}$ \\
\hline 6 & 30 & 4 & 2 & 2 & No & No & No & $\begin{array}{l}\text { Pelvic } \\
\text { pain+metrorrhagia }\end{array}$ & $7 \mathrm{WG}$ \\
\hline 7 & 34 & 2 & 1 & 1 & No & No & No & Metrorrhagia & $5 \mathrm{WG}$ \\
\hline 8 & 33 & 1 & 0 & 0 & No & No & No & Metrorrhagia & $6 \mathrm{WG}$ \\
\hline 9 & 23 & 1 & 0 & 0 & No & No & No & Metrorrhagia & $6 \mathrm{WG}$ \\
\hline 10 & 29 & 2 & 2 & 2 & No & No & No & Metrorrhagia & $5 \mathrm{WG}$ \\
\hline 11 & 34 & 2 & 0 & 0 & Yes & No & No & Ultrasound & $7 \mathrm{WG}+3 \mathrm{~d}$ \\
\hline 12 & 36 & 0 & 0 & 0 & No & Yes & No & $\begin{array}{l}\text { Pelvic } \\
\text { pain+metrorrhagia }\end{array}$ & $7 \mathrm{WG}+4 \mathrm{~d}$ \\
\hline 13 & 29 & 0 & 0 & 0 & No & No & No & Ultrasound & $7 \mathrm{WG}+6 \mathrm{~d}$ \\
\hline 14 & 26 & 0 & 0 & 0 & No & Yes & No & Ultrasound & $7 \mathrm{WG}+6 \mathrm{~d}$ \\
\hline 15 & 25 & 0 & 0 & 0 & No & Yes & No & Ultrasound & $7 \mathrm{WG}+6 \mathrm{~d}$ \\
\hline 16 & 26 & 1 & 1 & 1 & No & Yes & Yes & $\begin{array}{l}\text { Pelvic } \\
\text { pain+metrorrhagia }\end{array}$ & $7 \mathrm{WG}$ \\
\hline 17 & 28 & 1 & 1 & 1 & No & Yes & No & Pelvic pain & $9 \mathrm{WG}+4 \mathrm{~d}$ \\
\hline 18 & 29 & 1 & 0 & 0 & Yes & Yes & Yes & Ultrasound & 9WG \\
\hline
\end{tabular}

EP : Ectopic pregnancy, STI : Sexually Transmitted Infection, WG : Weeks'gestation, d : day

Table 2: Patients' outcomes.

\begin{tabular}{|c|c|c|c|c|}
\hline Case & $\begin{array}{l}\text { Initial hCG rate } \\
\text { (UI/L) }\end{array}$ & Outcome & 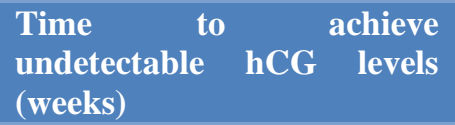 & $\begin{array}{l}\text { Time to become } \\
\text { pregnant (months) }\end{array}$ \\
\hline 1 & 3,491 & Success & 6.43 & - \\
\hline 2 & $1,62.5$ & Lost-to-follow-up & - & - \\
\hline 3 & 6,462 & Success & 8.14 & 7.6 \\
\hline 4 & 5,120 & Success & 3.29 & - \\
\hline 5 & 1,571 & Success & 6 & - \\
\hline 6 & 6,463 & Failure & - & - \\
\hline 7 & 915 & Failure & - & - \\
\hline 8 & 3,180 & Success & 5.3 & - \\
\hline 9 & 2,970 & Success & 4.5 & 9 \\
\hline 10 & $1,792.29$ & Success & 5.28 & 7.8 \\
\hline 11 & - & Failure & - & 6.8 \\
\hline 12 & $7,859.22$ & Success & 9.7 & - \\
\hline 13 & 1,704 & Lost-to-follow-up & - & - \\
\hline 14 & 1,800 & Success & 3.4 & 28 \\
\hline 15 & 25,287 & Success & 9.5 & 8.6 \\
\hline 16 & 10,460 & Failure & - & - \\
\hline 17 & 20,082 & Success & 5.7 & - \\
\hline 18 & 87,110 & Failure (rupture) & - & - \\
\hline
\end{tabular}




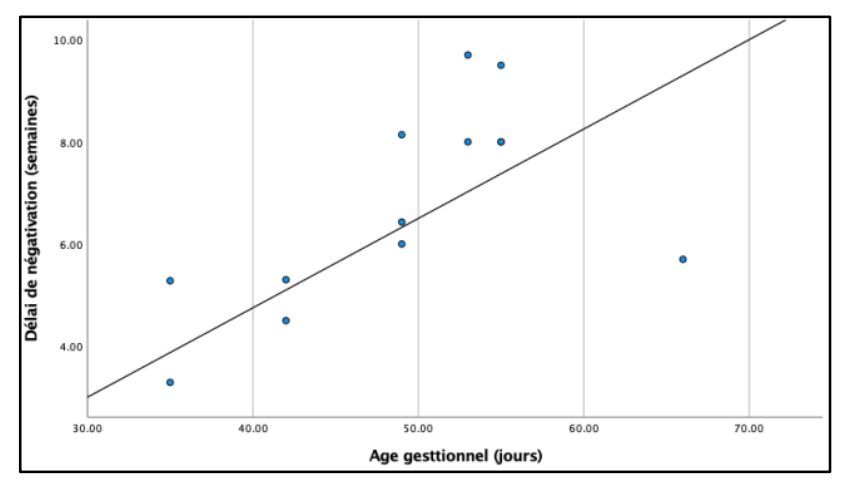

Figure 1: Correlation between time to denial and gestational age in days

Subsequently, 6 patients underwent pregnancy, 5 of which resulted in live births and one in an abortion. Only one patient had experienced methotrexate side effect (allergic vulvo-vaginitis).

\section{DISCUSSION}

\section{Main results}

Methotrexate given intramuscularly as a single dose of $50 \mathrm{mg} / \mathrm{m}^{2}$ is efficient in the treatment of ectopic pregnancy. This is moderately positively correlated with gestational age and not with baseline hCG levels.

\section{Interpretation of the results in the light of the international literature}

Methotrexate is the molecule of choice used in the medical treatment of ectopic pregnancy. Methotrexate is a folinic acid antagonist. ${ }^{10,11}$ It inhibits dihydrofolate reductase, an enzyme needed to convert dihydrofolic acid into tetrahydrofolic acid, thus preventing DNA synthesis and inhibiting cell multiplication. ${ }^{1}$ It was first used by Tanaka in 1982 in the treatment of interstitial ectopic pregnancy. The success rate of methotrexate ranges from 65 to $95 \% .^{6,12}$ Other molecules have been proposed such as potassium chloride or hyperosmolar glucose but their efficacy was $60 \%$ and $80 \%$ respectively. ${ }^{13,14}$ Three main treatment regimens have been described in the literature:

Single-dose intramuscular methotrexate regimen, multiple-dose intramuscular methotrexate regimen and in situ injection of methotrexate. The multiple-dose regimen involves the administration of four intramuscular doses of methotrexate $(1 \mathrm{mg} / \mathrm{kg})$ alternating with folinic acid $(0.1 \mathrm{mg} / \mathrm{kg}) .{ }^{15}$ The single-dose protocol involves a single administration of intramuscular methotrexate, followed by serum hCG measurement on days 4 and 7; if the hCG decrease is less than $15 \%$, a second dose of methotrexate is required. ${ }^{16}$ This protocol was developed to reduce the incidence of side effects after multiple dosing regimens, eliminating the need for folinic acid and increasing convenience of administration. ${ }^{17}$ The double-dose protocol involves the administration of two doses of methotrexate at D0 and D4, which was developed to combine the efficacy of multiple doses with the safety of single doses. ${ }^{18}$ In our series, without an established protocol for the medical management of ectopic pregnancies, the single-dose regimen was administered to all of our patients for its safety.

For the indications of medical treatment, certain criteria are consensual, namely an estimated hemoperitoneum of fewer than $100 \mathrm{ml}$, stable hemodynamics with normal hematocrit, a hematosalpinx size of less than $4 \mathrm{~cm}$, a $\beta$ hCG level of less than 5,000 IU/l and the absence of embryonic cardiac activity. ${ }^{1}$ Fernandez has proposed a pre-therapeutic score and recommends medical treatment if it is less than $13 .{ }^{19}$ However, there is no consensus on serum hCG levels. The 2007 meta-analysis by Hajenius et al. concluded that methotrexate is a treatment option for the medical treatment of low hCG ectopic pregnancies, although hCG levels are undefined. It ranges from $<5,000 \mathrm{IU} / \mathrm{L}$ to $<10,000 \mathrm{IU} / \mathrm{L}$ depending on the studies. $^{12}$ These recommendations seem justified considering that among the failures are those patients with the highest hCG levels, above 50,000 IU/ml. A level below 25,000 IU/L seems to be a reasonable option.

Certain conditions contraindicate medical treatment, namely lack of understanding of or compliance with follow-up, unstable hemodynamic status (pulse, blood pressure), extra-pelvic effusion on ultrasound, laparoscopy necessary for a definite diagnosis, history of homolateral ectopic pregnancy, tubal ectopic pregnancy with a size of more than $4 \mathrm{~cm}$ in diameter, presence of an embryo with cardiac activity. ${ }^{20,21}$ Nevertheless, cases of successful medical treatment for an unruptured ectopic pregnancy with a live embryo have been observed, which shows the relativity of the limits in the indications for medical treatment for an unruptured ectopic pregnancy. ${ }^{22}$

Regardless of the protocol used, rigorous clinical and biological monitoring is necessary. HCG measurement should be continued weekly until it falls below $15 \mathrm{IU} / \mathrm{ml}$. The time required to achieve undetectable $\beta$-hCG levels is variable. ${ }^{1}$ Persistent ectopic pregnancy occurs when the hCG level rises. ${ }^{23}$ In our series the time to achieve undetectable $\beta$-hCG levels was 6.7 weeks. The subsequent safety of methotrexate on fertility has been proven by its use in patients with trophoblastic tumors since the 1970s. ${ }^{1}$ In these women, there was no increased risk of miscarriage or increased risk of birth defects or cancer. $^{7}$ In fact, 5 pregnancies were recorded in our series. The success rate of methotrexate ranged from $65-$ $95 \% .{ }^{12}$ Several studies have shown comparable efficacy of medical treatment compared to surgical treatment in unruptured ectopic pregnancies. ${ }^{7,12,24,25}$ Our success rate was comparable to those found in single-dose protocols. ${ }^{1}$

\section{Implications for practice and research}

The indications for medical treatment are still subject to discussion. Most of the reported series are of small 
sample sizes, which reduces their statistical power. Multicenter studies are therefore necessary in order to establish strong criteria for the selection of patients to be included. Patient advice should also be required, as medical treatment requires longer follow-up. Regarding cost, only studies evaluating the cost of conservative treatment of ectopic pregnancy are currently available. In these studies, the overall cost of medical treatment was lower than that of conservative surgical treatment thanks to a reduction in the duration of hospitalization. This financial advantage, however, was only verified for the early discovery forms: when the initial plasma hCG level was less than $3000 \mathrm{mIU} / \mathrm{L}$ in Mol's work, and 1,500 $\mathrm{mIU} / \mathrm{L}$ in Sowter's study. ${ }^{26,27}$ Furthermore, in terms of quality of life, a randomized study comparing treatment with methotrexate with laparoscopic salpingotomy reported poorer tolerance to medical treatment. ${ }^{28}$

\section{Strengths and limitations}

A strength of our study is that it is based on a large dataset in the leading maternities in Dakar.

However, this was a retrospective study. The data was taken from our E-Perinatal databases. The main limitation was the existence of incomplete files. It happened that certain parameters were not correctly recorded, which could be the origin of a bias.

\section{CONCLUSION}

The treatment of ectopic pregnancy, which used to be exclusively surgical, has evolved with the possibility of medical treatment. Methotrexate is now part of the therapeutic arsenal in the management of unruptured tubal ectopic pregnancies. However, in developing countries, particularly in Senegal, there is a reluctance to use this therapeutic method, which, however, when a personalized follow-up is carried out, is achievable with a success rate comparable to other therapeutic methods.

\section{Funding: No funding sources}

Conflict of interest: None declared

Ethical approval: The study was approved by the Institutional Ethics Committee

\section{REFERENCES}

1. Dupuis O, Camagna O, Benifla JL, Batallan A, Renolleau C, Madelenat P. Grossesse extra-utérine. 2001;5:30-2.

2. Xia Q, Wang T, Xian J, Song J, Qiao Y, Mu Z, et al. Relation of Chlamydia trachomatis infections to ectopic pregnancy: a meta-analysis and systematic review. Medicine Janv. 2020;99(1):e18489.

3. Bruhat MA, Manhes H, Mage G, Pouly JL. Treatment of ectopic pregnancy by means of laparoscopy. Fertil Steril. 1980;33(4):411-4.
4. Dubuisson JB, Aubriot FX, Cardone V. Laparoscopic salpingectomy for tubal pregnancy. Fertil Steril. 1987;47(2):225-8.

5. Agdi M, Tulandi T. Surgical treatment of ectopic pregnancy. Clin Obstet Gynaecol. 2009;23(4):519-27.

6. Tanaka T, Hayashi H, Kutsuzawa T, Fujimoto S, Ichinoe $\mathrm{K}$. Treatment of interstitial ectopic pregnancy with methotrexate: report of a successful case. Fertil Steril. 1982;37(6):851-2.

7. Rongières C. Grossesse extra-utérine: pour le traitement. Conservateur Médical. 2007;4:87-9.

8. Altaras M, Cohen I, Cordoba M, Nun I, Aderet N. Treatment of an interstitial pregnancy with actinomycin D. Case report. 1988;95(12):1321-3.

9. Marret H, Fauconnier A, Dubernard G, Misme H, Lagarce L, Lesavre $\mathrm{M}$, et al. Evidence-based evaluation and expertise of methotrexate off label use in gynaecology and obstetrics: work of the CNGOF. J Gynecol Obstet Biol Reprod. 2015;44(3):230-6.

10. Barnhart K, Coutifaris C, Esposito M. The pharmacology of methotrexate. Expert Opin Pharmacother. 2001;2(3):409-17.

11. Brown DL, Felker RE, Stovall TG, Emerson DS, Ling FW. Serial endovaginal sonography of ectopic pregnancies treated with methotrexate. Obstet Gynecol. 1991;77(3):406-9.

12. Hajenius PJ, Mol F, Mol BWJ, Bossuyt PMM, Ankum WM, Veen F. Interventions for tubal ectopic pregnancy. Cochrane Database Syst Rev. 2007;(1):CD000324.

13. Robertson DE, Smith W, Moye MA, Brinsden PR, Hansen JN, Lewis PM, et al. Reduction of ectopic pregnancy by injection under ultrasound control. Lancet Lond Engl. 1987;1(8539):974-5.

14. Laatikainen T, Tuomivaara L, Käär K. Comparison of a local injection of hyperosmolar glucose solution with salpingostomy for the conservative treatment of tubal pregnancy. Fertil Steril. 1993;60(1):80-4.

15. Lipscomb GH, Stovall TG, Ling FW. Nonsurgical treatment of ectopic pregnancy. $\mathrm{N}$ Engl $\mathrm{J}$ Med. 2000;343(18):1325-9.

16. Stovall TG, Ling FW, Gray LA. Single-dose methotrexate for treatment of ectopic pregnancy. Obstet Gynecol. 1991;77(5):754-7.

17. Barnhart KT, Gosman G, Ashby R, Sammel M. The medical management of ectopic pregnancy: a metaanalysis comparing single dose and multidose regimens. Obstet Gynecol. 2003;101(4):778-84.

18. Barnhart K, Hummel AC, Sammel MD, Menon S, Jain J, Chakhtoura N. Use of 2-dose regimen of methotrexate to treat ectopic pregnancy. Fertil Steril. 2007;87(2):250-6.

19. Gervaise A, Fernandez H. Prise en charge diagnostique et thérapeutique des grossesses extrautérines. J Gynécologie Obstétrique Biol Reprod. 2010;3:17-24.

20. Lesavre M, Curinier S, Capmas P, Rabischong B, Fernandez H. Utilisation du méthotrexate dans les 
GEU tubaires. J Gynécologie Obstétrique Biol Reprod. 2008;44:212-19.

21. Lipscomb GH, Bran D, McCord ML, Portera JC, Ling FW. Analysis of three hundred fifteen ectopic pregnancies treated with single-dose methotrexate. Am J Obstet Gynecol. 1998;178(6):1354-8.

22. Gassama O, Dieme MF, Diallo M, Niang MM. Traitement médical d'une grossesse extra-utérine tubaire avec embryon: à propos d'un cas au Centre de Santé Nabil Choucair(Dakar ,Sénégal)T. J Sago. 2015;16(2):45-9.

23. Practice Committee of the American Society for Reproductive Medicine. Medical treatment of ectopic pregnancy. Fertil Steril. 2006;86(51):96-102.

24. Moeller LB, Moeller C, Thomsen SG, Andersen LF, Lundvall L, Lidegaard $\varnothing$, et al. Success and spontaneous pregnancy rates following systemic methotrexate versus laparoscopic surgery for tubal pregnancies: a randomized trial. Acta Obstet Gynecol Scand. 2009;88(12):1331-7.

25. Mol F, Mol BW, Ankum WM, Veen F, Hajenius PJ. Current evidence on surgery, systemic methotrexate and expectant management in the treatment of tubal ectopic pregnancy: a systematic review and metaanalysis. Hum Reprod. 2008;14(4):309-19.

26. Mol BW, Hajenius PJ, Engelsbel S, Ankum WM, Hemrika DJ, Veen F, et al. Treatment of tubal pregnancy in the netherlands: an economic comparison of systemic methotrexate administration and laparoscopic salpingostomy. Am J Obstet Gynecol. 1999; 181(4):945-51.

27. Sowter MC, Farquhar CM. Ectopic pregnancy: an update. Curr Opin Obstet Gynecol. 2004;16(4):289-93.

28. Nieuwkerk PT, Hajenius PJ, Ankum WM, Veen F, Wijker W, Bossuyt PM. Systemic methotrexate therapy versus laparoscopic salpingostomy in patients with tubal pregnancy. Part I. Impact on patients' health-related quality of life. Fertil Steril. 1998;70(3):511-7.

Cite this article as: Ndour SB, Gueye M, Diouf AA, Diallo M. Medical management of ectopic pregnancy in a low resource setting: the role of methotrexate. Int J Reprod Contracept Obstet Gynecol 2021;10:87984. 